\title{
Service-induced Changes in the Microstructure and Mechanical Properties of a $\mathrm{Cr}-\mathrm{Mo}-\mathrm{Ni}-\mathrm{V}$ Turbine Steel
}

\author{
Mitsuo YAMASHITA, U. K. VISWANATHAN, ${ }^{1)}$ Isamu YAMAMOTO ${ }^{2)}$ and Toshiro KOBAYASHI ${ }^{3)}$
}

Production Technology Laboratory, Fuji Electric Co., Ltd., Tanabeshinden, Kawasaki-ku, Kawasaki, Kanagawa-ken, 210 Japan. $\quad 1$ 1) Radiometallurgy Division, Bhabha Atomic Research Centre, Trombay, Bombay 400085, India.

2) Department of Technology, Osaka Kyoiku University, Asahigaoka, Kashiwara, Osaka-fu, 582 Japan.

3) Department of Production Systems Engineering, Toyohashi University of Technology, Tempaku-cho, Toyohashi, Aichi-ken, 441 Japan.

(Received on May 22, 1997; accepted in final form on July 11, 1997)

\begin{abstract}
The effect of service temperature on the degradation of mechanical properties of a low alloy $\mathrm{Cr}-\mathrm{Mo}-\mathrm{Ni}-\mathrm{V}$ steel applied for turbine rotor, retired after 15.8 years of service was evaluated and supplemented with the results from microstructural and fractographic examinations. Maximum embrittlement, manifested as decrease in upper shelf energy and increase in ductile-to-brittle transition temperature had occurred at a service temperature of $714 \mathrm{~K}$ and the material serviced at $811 \mathrm{~K}$ exhibited relatively better toughness. A re-aging treatment at $811 \mathrm{~K}$ for $24 \mathrm{~h}$ partially recovered the loss in toughness. The dominant carbides identified were $\mathrm{M}_{23} \mathrm{C}_{6}$ and $\mathrm{M}_{6} \mathrm{C}$, enriched with chromium and iron, and molybdenum and iron, respectively and $\mathrm{M}_{2} \mathrm{C}$ with molybdenum and vanadium as the major metallic constituents. Coarsening of carbides occurred with increasing temperature through carbide reactions. The embrittled material showed the presence of coarse $\mathrm{M}_{23} \mathrm{C}_{6}$ carbides along the prior-austenite grain boundaries. However, material serviced at $811 \mathrm{~K}$ contained relatively less coarse grain boundary precipitates. Homogeneous precipitation of fine carbides of $\mathrm{M}_{2} \mathrm{C}$ type also occurred at this temperature through carbide reactions. Re-aging of the embrittled material led to partial dissolution of grain boundary carbides and also to copious precipitation of $\mathrm{M}_{2} \mathrm{C}$ type of carbide. Observed changes in mechanical properties are partly attributed to the in-service evolution of carbides and partly attributed to segregation of impurities at grain boundary.
\end{abstract}

KEY WORDS: grain boundary; grain size; toughness; low alloy steel; turbine rotor; service-induced degradation; carbide reaction; segregation.

\section{Introduction}

Low-alloy ferritic steels of the type $\mathrm{Cr}-\mathrm{Mo}$ and $\mathrm{Cr}-$ Mo-Ni-V steel are widely being used as high temperature structural components in electric power generation industries because of optimum combination of their good mechanical properties and relatively low cost. The mechanical properties of these steels are basically derived from the distribution of different types of carbides, produced during the initial heat treatments. However, they are susceptible to degradation of mechanical properties, on prolonged exposure to elevated temperatures. ${ }^{1-10)}$ The extent of degradation depends upon the microstructure of the steel, the type and distribution of carbides and the cleanliness of the steel with respect to the impurity content.

Two types of embrittlement are generally noticed; namely (i) embrittlement due to the segregation of impurities to the grain boundaries ${ }^{2,6)}$ and (ii) embrittlement due to microstructural changes in the type and morphology of carbides evolved during service. The carbide-induced embrittlement is manifested as decrease in the impact toughness, without affecting the ductile- to-brittle transition temperature (DBTT) and is reported to be irreversible. The loss in toughness is usually accompanied with softening of the material. The segregation-induced embrittlement, generally known as temper embrittlement, on the other hand, induces an increase in the transition temperature and is reversible. Of the impurities, it is fairly well established that phosphorous is the most critical element and the roles of other impurity elements are to promote the segregation of the former. ${ }^{11}$ )

In this paper, the changes in the mechanical properties of a $\mathrm{Cr}-\mathrm{Mo}-\mathrm{Ni}-\mathrm{V}$ turbine rotor, retired after 15.8 years of operation are evaluated by carrying out Charpy Vnotch impact test and hardness test on samples from different locations of the rotor, where the service temperatures were $333,541,714$ and $811 \mathrm{~K}$. The result is mainly supplemented with the microstructural details of carbides evolved at these temperatures. A qualitative amount of $\mathbf{P}$ segregation at grain boundaries estimated by the grain boundary etching method ${ }^{12)}$ and fractographic features are also considered. 


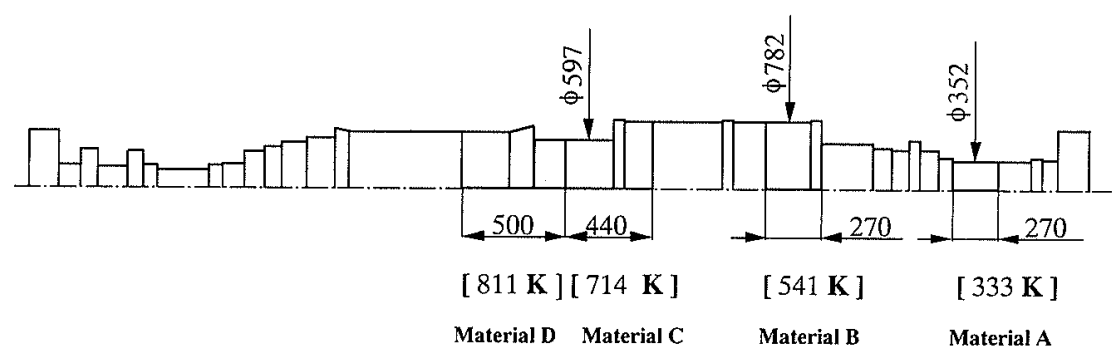

Fig. 1. Schematic diagram of turbine rotor with sample locations.

Table 1. Chemical composition of the steel. (wt\%)

\begin{tabular}{cccccccccccccccc}
\hline $\mathrm{C}$ & $\mathrm{Cr}$ & $\mathrm{Mo}$ & $\mathrm{Ni}$ & $\mathrm{V}$ & $\mathrm{Si}$ & $\mathrm{Mn}$ & $\mathrm{Cu}$ & $\mathrm{P}$ & $\mathrm{Sn}$ & $\mathrm{As}$ & $\mathrm{Sb}$ & $\mathrm{S}$ & $\mathrm{Ti}$ & $\mathrm{Al}$ \\
\hline 0.21 & 1.21 & 1.08 & 0.68 & 0.28 & 0.33 & 0.74 & 0.16 & 0.006 & 0.017 & 0.02 & 0.005 & 0.005 & $<0.02$ & 0.005 \\
\hline
\end{tabular}

\section{Experimental Procedure}

\subsection{Material}

Material for this investigation was taken from a $\mathrm{Cr}-\mathrm{Mo}-\mathrm{Ni}-\mathrm{V}$ rotor, retired from service after 15.8 years of operation. Coupons used for the investigation were removed from locations where the service temperatures were $333,541,714$ and $811 \mathrm{~K}$, as shown schematically in Fig. 1. The chemical composition of the steel is given in Table 1. Since the virgin material or the initial heat treatment is not available, the material serviced at $333 \mathrm{~K}$ is considered to represent the original material. A laboratory re-aging was carried out at $811 \mathrm{~K}$ for $24 \mathrm{~h}$ on part of the coupon serviced at $714 \mathrm{~K}$.

\subsection{Mechanical Tests}

Standard Charpy V-notch specimens (thickness: 10 $\mathrm{mm}$, width: $10 \mathrm{~mm}$, length: $55 \mathrm{~mm}$, notch depth: $2 \mathrm{~mm}$ ) were fabricated with the long axis of the specimen being parallel to the axis of the rotor and the notch being cut along the circumferential direction of the rotor. Impact tests were conducted as per ASTM E23, ${ }^{13)}$ over a range of temperatures to generate full transition curve. The DBTT was estimated from the average of the upper shelf energy (USE) and the lower shelf energy (LSE). The specimens for hardness tests were prepared from the undeformed ends of the broken impact specimens and the hardness was measured on the Vickers scale with an indentation load of $98 \mathrm{~N}$.

\subsection{Metallography}

Samples for metallography were chemically etched using an electrolyte of $2 \%$ nital. Microstructural examination was carried out by using a scanning electron microscope (SEM) at an operating voltage of $20 \mathrm{kV}$. Characterization of carbides was performed on extraction replica. A carbon coating of approximately $20 \mathrm{~nm}$ was deposited onto the etched specimen under a vacuum of $1.3 \times 10^{-3} \mathrm{~Pa}$. The carbides were extracted electrolytically using an electrolyte of $10 \% \mathrm{HCl}$ and $90 \%$ methanol at $2 \mathrm{~V}$ d.c.. The microanalysis of the precipitates was carried out by using a $200 \mathrm{kV}$ scanning transmission electron microscope (STEM), equipped with energydispersive $\mathrm{X}$-ray analysis (EDAX) facility. Selected area diffraction (SAD) technique was used for carbide iden-

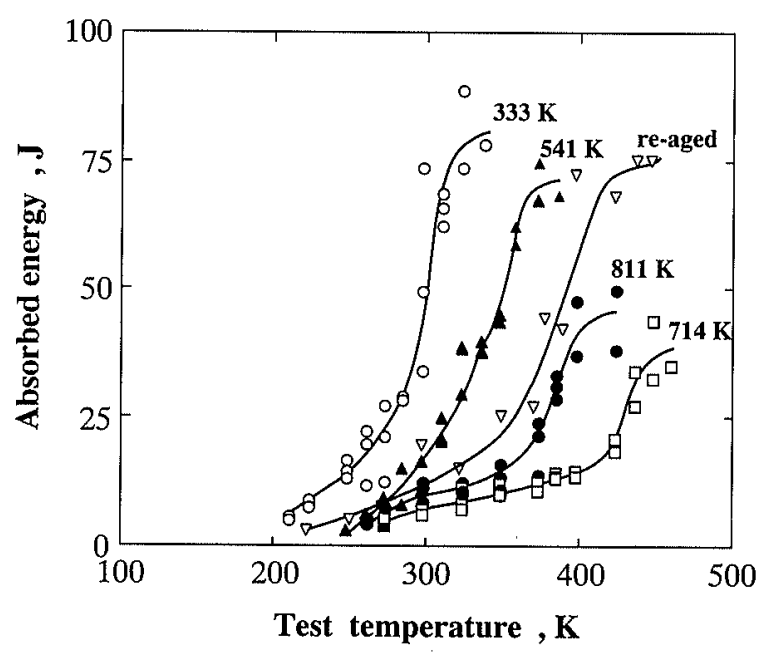

Fig. 2. Absorbed energy as a function of test temperature.

tification. Fracture surfaces of impact specimens were observed under SEM, operated at $20 \mathrm{kV}$. The qualitative amount of $\mathrm{P}$ segregation at grain boundaries was estimated by the grain boundary etching method. The etching was performed at $293 \mathrm{~K}$ for $1.8 \mathrm{ks}$ in the stirred etching solution: $100 \mathrm{~g}$ saturated aqueous solution of picric acid containing $1 \mathrm{~g}$ sodium tridencylbenzene sulfonate. The surface of an etched sample was marked with micro-Vickers indentations and then polished mechanically by using $\mathrm{Al}_{2} \mathrm{O}_{3}$-powders of $0.05 \mu \mathrm{m}$ in mean diameter until the traces of etched grain boundaries, of which groove depths were to be measured, disappeared. The measurement of the sizes of the microVickers indentations before and after the polishing made it possible to calculate the groove depths of any grain boundaries.

\section{Results and Discussion}

\subsection{Effect of Temperature on Toughness}

The absorbed energy as a function of test temperature is shown in Fig. 2. A progressive shift of the transition curves to the right, indicating the gradual loss in toughness with increasing service temperature, was observed up to $714 \mathrm{~K}$. However, a reversal in this trend was shown by the material serviced at $811 \mathrm{~K}$, which 


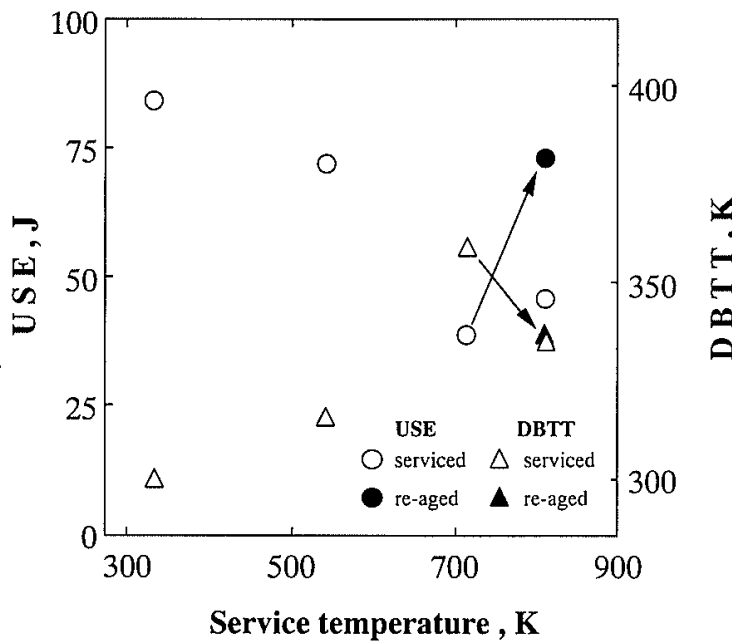

Fig. 3. Upper shelf energy (USE) and ductile-brittle transition temperature (DBTT) as functions of service temperature.

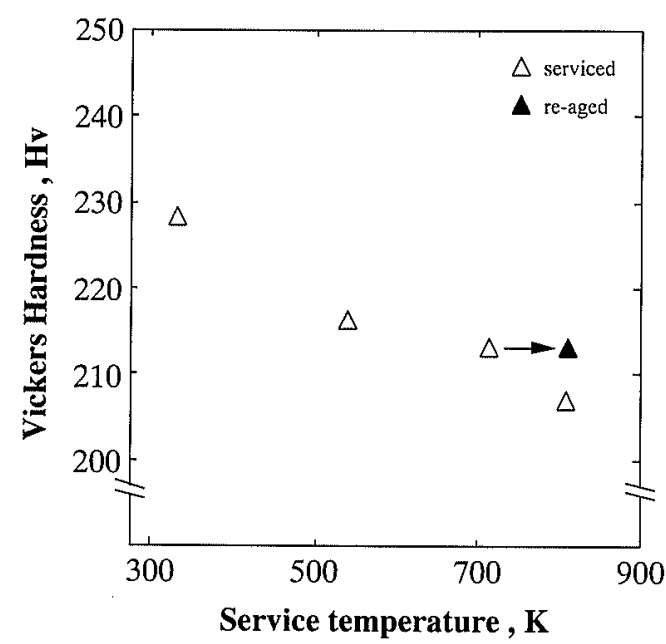

Fig. 4. Vickers hardness number as a function of service temperature.

exhibited better toughness than the material serviced at $714 \mathrm{~K}$. The effect of re-aging on the recovery of toughness can be appreciated from the relative position of the transition curve obtained from the re-aged specimens, as shown in Fig. 2. The DBTT and USE, estimated from Fig. 2 are plotted against the service temperature as shown in Fig. 3. The occurrence of maximum embrittlement, at $714 \mathrm{~K}$ is reflected by the location of their respective maximum and minimum at that temperature. The decrease in DBTT and the significant increase in USE, produced by re-aging can also be realized from Fig. 3.

\subsection{Effect of Temperature on Hardness}

The hardness of the samples, plotted as a function of service temperature is shown in Fig. 4. The hardness of the re-aged sample is also shown in the figure. Decrease in hardness, though marginal, was continuous with increasing service temperature. It can be noted from the figure that the re-aging did not produce any further decrease in hardness of the material serviced at $714 \mathrm{~K}$.

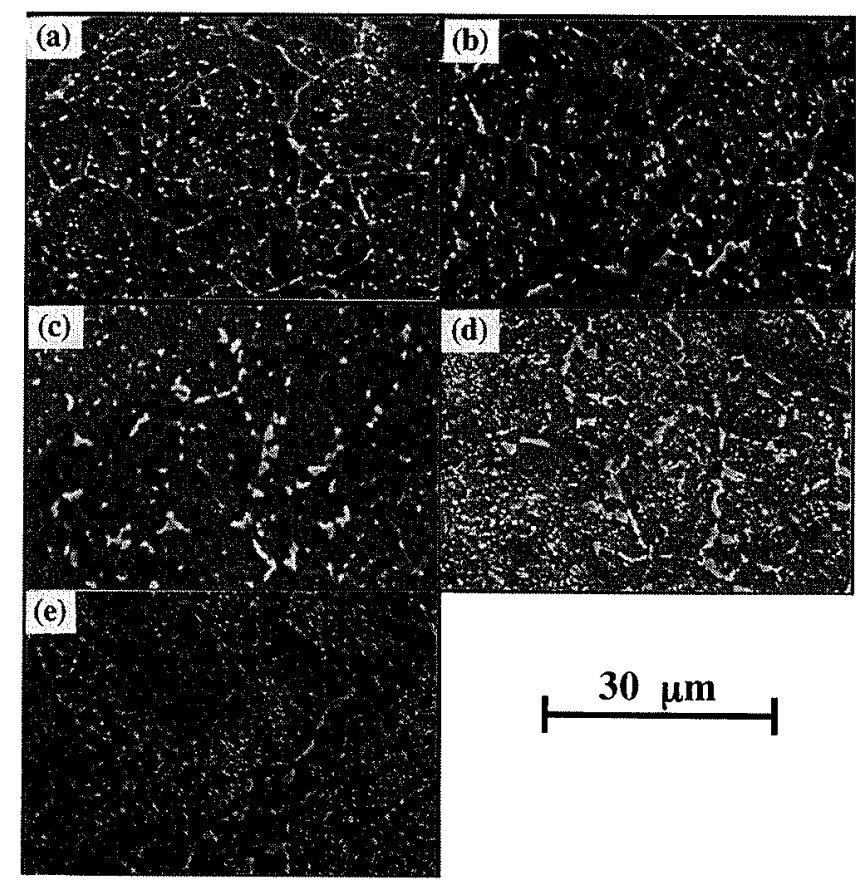

Fig. 5. SEM microstructure of each sample. (a) Material A (serviced at $333 \mathrm{~K}$ ) (b) Material B (serviced at $541 \mathrm{~K}$ ) (c) Material C (serviced at $714 \mathrm{~K}$ ) (d) Material D (serviced at $811 \mathrm{~K}$ ) and (e) Material E (re-aged material C at $811 \mathrm{~K}$ ).

\subsection{Microstructure}

Microstructures of the samples serviced at different temperatures and the microstructure of the re-aged sample, as revealed by SEM are shown in Fig. 5. The prior-austenite grains were non uniform and the grain size varied from 10 to $20 \mu \mathrm{m}$. Carbides were precipitated within grains and along the prior-austenite grain boundaries. Continuous coarsening of carbides occurred with increasing service temperature. Microstructure of the sample serviced at $714 \mathrm{~K}$ showed the presence of thick precipitates along the grain-boundaries. Sample serviced at $811 \mathrm{~K}$ contained homogeneously distributed fine precipitates. Grain boundary precipitates appeared to be less in this sample, compared to the sample serviced at $714 \mathrm{~K}$. Re-aging produced very fine precipitates, morphologically similar to the type seen in sample serviced at $811 \mathrm{~K}$. It was also observed that the re-aging has dissolved or fragmented part of the coarse grain-boundary precipitates formed at $714 \mathrm{~K}$, as can be noticed from Fig. 5.

\subsection{Morphology and Composition of Carbides}

The morphology and distribution of carbides, presented in a composite form, at different service temperatures is shown in Fig. 6 shows that of the re-aged sample. Depending on the prominence of their metallic constituents, the carbides were classified into the following three categories: carbides enriched with (i) iron and chromium (ii) iron and molybdenum, and (iii) molybdenum and vanadium. The respective EDAX spectra, recorded from these carbides are shown in Fig. 7. From the SAD patterns obtained, they were identified as $\mathrm{M}_{23} \mathrm{C}_{6}, \mathrm{M}_{6} \mathrm{C}$ and $\mathrm{M}_{2} \mathrm{C}$ types of carbides, respectively. The sample serviced at $333 \mathrm{~K}$ contained rod shaped and 


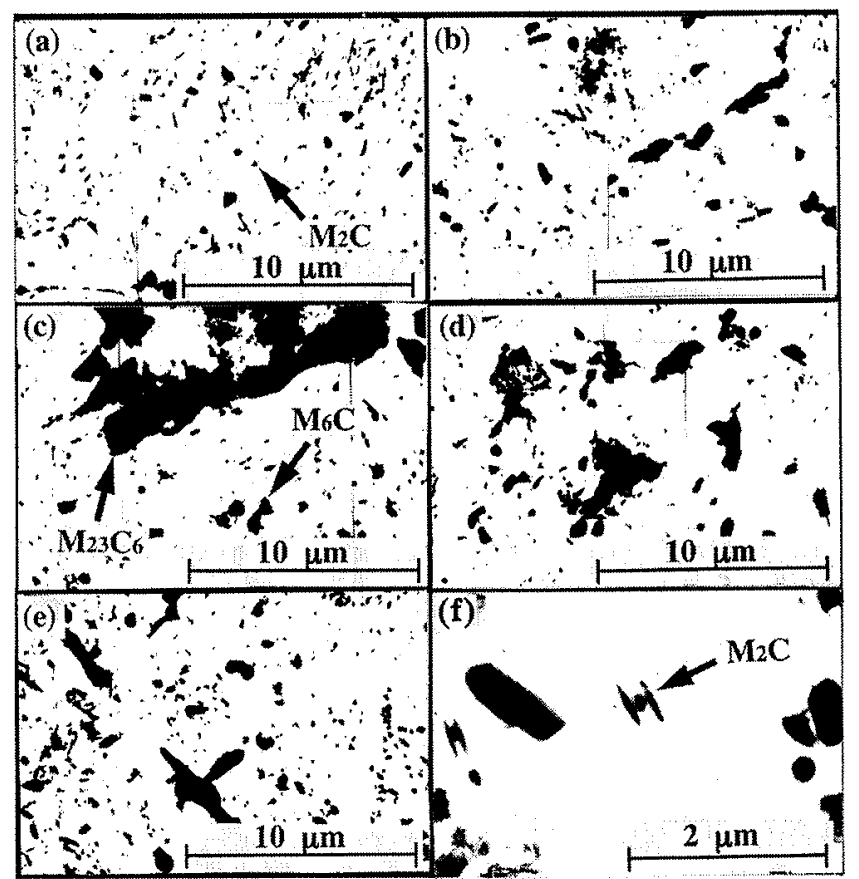

Fig. 6. Morphology and distribution of carbides in each sample. (a) Material A (serviced at $333 \mathrm{~K}$ ) (b) Material $\mathrm{B}$ (serviced at $541 \mathrm{~K}$ ) (c) Material C (serviced at $714 \mathrm{~K}$ ) (d) Material D (serviced at $811 \mathrm{~K}$ ) (e) Material E (re-aged material $\mathrm{C}$ at $811 \mathrm{~K}$ ) and (f) Typical $\mathrm{M}_{2} \mathrm{C}$ type of carbide in Material A.

spheroidal carbides of $\mathrm{M}_{23} \mathrm{C}_{6}$ and $\mathrm{M}_{6} \mathrm{C}$ types as shown in Fig. 6. Preferential precipitation along the grainboundaries of $\mathrm{M}_{23} \mathrm{C}_{6}$, with irregular morphology was noticed. $\mathrm{M}_{2} \mathrm{C}$ carbides with $\mathrm{H}$-morphology were frequently noticed, and is shown by arrow in Fig. 6. Coarsening of the carbides in general and the grain-boundary carbides in particular, occurred with increasing temperature, as can be noted from Fig. 6 . At $811 \mathrm{~K}$, however, the grain boundary carbides appeared to have fragmented and their distribution along the boundaries was found to be more discontinuous. This was clearly observed in the microstructure of the re-aged sample, shown in Fig. 6. Re-aging also led to fresh precipitation of $\mathrm{M}_{2} \mathrm{C}$ carbides with $\mathrm{H}$-type and spheroidal morphologies. Occurrence of partial dissolution of grain boundary carbides was also noticed at the re-aging temperature, as can be observed from their fragmented appearance in Fig. 6.

\subsection{Segregation of Impurities}

The grain boundary etching depth at different temperatures is shown in Fig. 8. The grain boundary etching depth measured is increasing with increasing temperature up to $714 \mathrm{~K}$. However grain boundary etching depths of the material serviced at $811 \mathrm{~K}$ and reaged sample are reduced. Good relationship between intergranular impurity concentration and the degree of grain boundary etching is reported by Ogura and coworkers. ${ }^{12)}$ So remarkable $\mathrm{P}$ segregation is mainly estimated in material serviced at $714 \mathrm{~K}$. And it is suggested that the improvement of toughness by reaging is, in some portions, due to the change of $\mathrm{P}$ segregation state at grain boundaries.

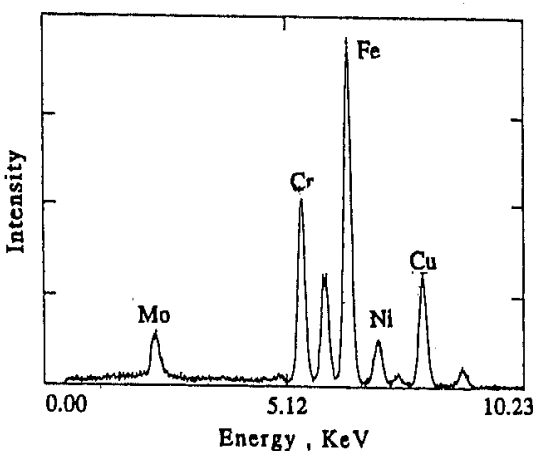

M23 $\mathrm{C}_{6}$ carbide

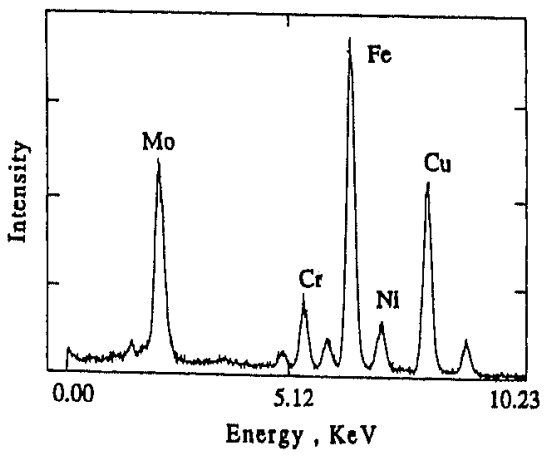

MoC carbide

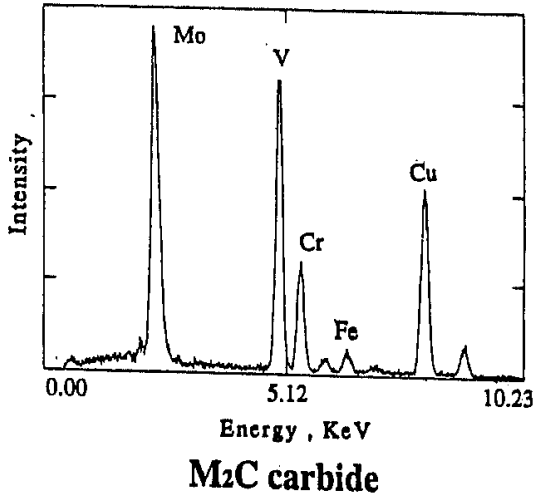

Fig. 7. Typical EDAX spectrum of each carbide.

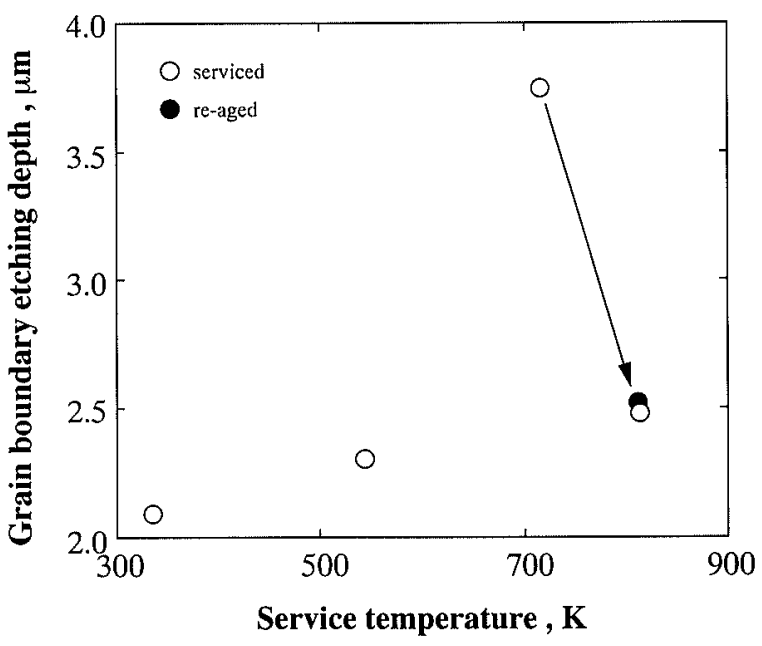

Fig. 8. Grain boundary etching depth as a function of service temperature. 


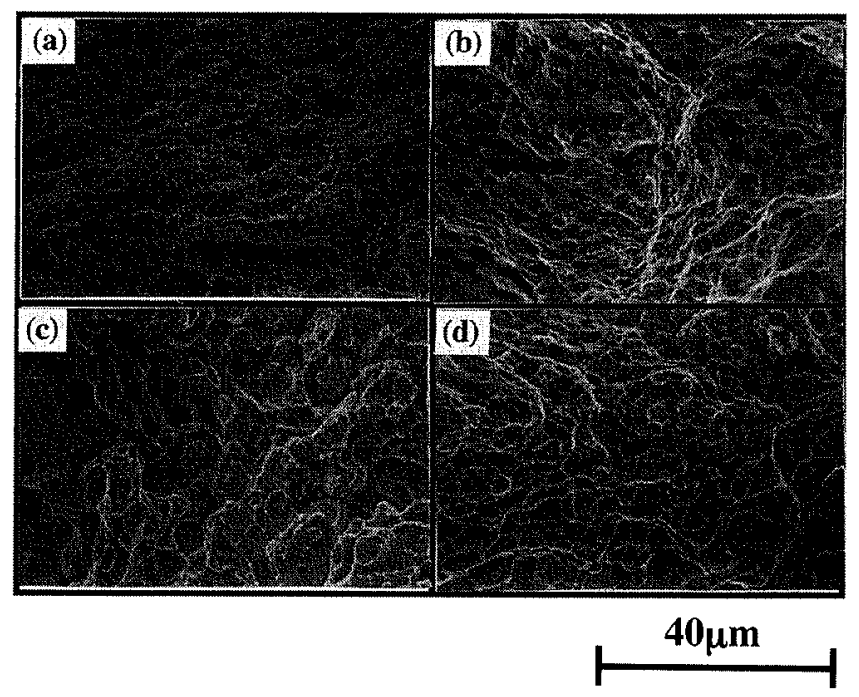

Fig. 9. Fracture surfaces at upper shelf energy level. (a) Material A (serviced at $333 \mathrm{~K}$ ) (b) Material B (serviced at $54 \mathrm{~K}$ ) (c) Material $\mathrm{C}$ (serviced at $714 \mathrm{~K}$ ) and (d) Material D (serviced at $811 \mathrm{~K}$ ).
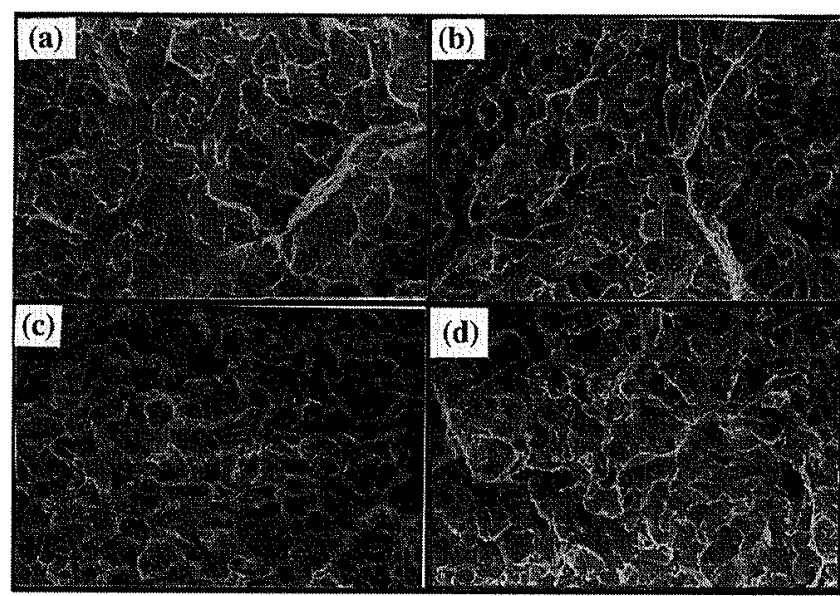

$40 \mu \mathrm{m}$

Fig. 10. Fracture surfaces at lower shelf energy level. (a) Material A (serviced at $333 \mathrm{~K}$ ) (b) Material B (serviced at $541 \mathrm{~K}$ ) (c) Material C (serviced at $714 \mathrm{~K}$ ) and (d) Material D (serviced at $811 \mathrm{~K}$ ).

\subsection{Fractography}

Fractographs of impact specimens, from material serviced at different temperatures at USE and LSE are shown in Figs. 9 and $\mathbf{1 0}$ respectively.

Coarsening of dimples occurred with increasing temperature up to $714 \mathrm{~K}$. However fractograph of the material serviced at $811 \mathrm{~K}$ contained fine dimples (Fig. 9).

The fractographs of the samples serviced at 333,541 and $811 \mathrm{~K}$ contained dimples and cleavage facets showing river patterns. However fractograph of serviced sample at $714 \mathrm{~K}$ showed inter-granular separation and the continuous cracking (Fig. 10).

\section{Discussion}

The carbides present in the original microstructure were chromium-rich $\mathrm{M}_{23} \mathrm{C}_{6}$, molybdenum-rich $\mathrm{M}_{6} \mathrm{C}$ and $\mathrm{M}_{2} \mathrm{C}$ carbides enriched with molybdenum and vanadium. $\mathrm{M}_{23} \mathrm{C}_{6}$ carbides showed a preference to form along the prior-austenite grain-boundaries. The presence of $\mathrm{M}_{23} \mathrm{C}_{6}$ carbides in this steel is in variance with the findings of Goldhoff and Beattie ${ }^{14)}$ and Jorder and co-workers. ${ }^{10)}$ Also, the $\mathrm{Fe}_{3} \mathrm{C}$ type of carbide, reported in their work was totally absent in this steel. This difference could be due to the difference in the chemical composition and the initial heat treatment, which in the present case is not known. The presence of $\mathrm{M}_{2} \mathrm{C}$ type of carbides with $\mathrm{H}$-morphology is reported by several investigators. ${ }^{15,16)}$ The typical morphology is acquired by the formation of $\mathrm{Mo}_{2} \mathrm{C}$ carbides as wings on pre-existing vanadium rich carbides. ${ }^{16)}$

The carbides formed during the initial tempering treatments were unstable during service. Even at $541 \mathrm{~K}$, which is evidently below the original tempering temperature, considerable coarsening of carbides had occurred; the effect being more pronounced in the case of grain-boundary carbides. Similar microstructural changes were noticed by Liaw and co-workers in a 2-1/4 $\mathrm{Cr}-1 \mathrm{Mo}$ steel serviced for 22 years. ${ }^{17)}$ In contrast, Joarder and co-workers did not find any microstructural changes at $541 \mathrm{~K}$ even after 23 years of service. ${ }^{10)}$ However, at $811 \mathrm{~K}$ the coarse grain-boundary carbides appeared to have been reduced in number. The microstructure of the re-aged sample suggested that most of the grainboundary carbides were either dissolved or fragmented, during re-aging at $811 \mathrm{~K}$. Re-aging also resulted in the precipitation of molybdenum and vanadium rich $\mathrm{M}_{2} \mathrm{C}$ carbides, of the type noticed in sample serviced at $811 \mathrm{~K}$. Copious precipitation of $\mathrm{M}_{2} \mathrm{C}$ carbides is reported at this temperature by Joarder and co-workers ${ }^{10)}$ and by Williams and co-workers. ${ }^{16)}$

The steel used in this work possessed low initial DBTT and better USE than that reported on similar type of steel by other investigators. ${ }^{7)}$ This could be due to relatively high nickel content of this steel. Presence of nickel is generally accepted to be beneficial to improve the notch-toughness and is known to be particularly effective in lowering the ductility-transition temperature. ${ }^{18)}$ The magnitude of degradation in toughness, in terms of increase in DBTT and decrease in USE is also found to be lower in the present case compared to those reported in similar type of steel. ${ }^{2)}$

Coarsening of the carbides in general and dimples of fracture surfaces at upper shelf energy occurred with increasing temperature, as can be noted from Figs. 5 and 9 respectively. Generally, carbide is the site of evoked dimple in the steel. In this work, this phenomenon was observed, and toughness was decreasing with increasing temperature.

On the other hand, the segregation of impurities to the grain boundaries will lead to decreasing the binding energy of the grain boundaries. In this work, the continuous cracking along the grain boundaries was observed with increasing remarkable $\mathbf{P}$ segregation to the grain boundaries at a service temperature of $714 \mathrm{~K}$. It is suggested that re-aging treatment at $811 \mathrm{~K}$ will also improve this grain boundary embrittlement. 


\section{Conclusions}

Based on the results from this investigation, the following conclusions are drawn:

(1) Maximum embrittlement, manifested as decrease in upper shelf energy and increase in ductile-to-brittle transition temperature had occurred with maximum coarsening carbides and maximum $\mathrm{P}$ segregation at a service temperature of $714 \mathrm{~K}$.

(2) The carbides present in the microstructure were $\mathrm{M}_{23} \mathrm{C}_{6}, \mathrm{M}_{6} \mathrm{C}$ and $\mathrm{M}_{2} \mathrm{C}$ and their proportion depended on the service temperature. $M_{23} C_{6}$ and $M_{6} C$ types of carbides were present at all temperatures, and coarsened with increasing temperature up to $714 \mathrm{~K}$. However, $\mathrm{M}_{2} \mathrm{C}$ type of carbide was fine at any temperature and the proportion of $\mathrm{M}_{2} \mathrm{C}$ type of carbide increased significantly at $811 \mathrm{~K}$.

(3) Re-aging of the embrittled material led to increasing toughness with partial dissolution of the grain boundary carbides and also copious precipitation of $\mathrm{M}_{2} \mathrm{C}$ type of carbide, without loss of hardness. Moreover grain boundary embrittlement due to segregation of impurity elements is also improved.

\section{Acknowledgments}

The authors would like to thank Prof. Y. Murata of Nagoya University for his help to conduct TEM observation. They also thank to Mr. T. Ono for his experimental work.

\section{REFERENCES}

1) R. Viswanathan and A. Joshi: Metall. Trans. A, 6A (1975), 2289.

2) N. S. Cheruvu: Metall. Trans. A, 20A (1989), 87.

3) M. Holzmann, J. Man and B. Vlach: Int. J. Pressure Vessels Piping, 57 (1994), 141.

4) Z. G. Wang, K. Rakha, P. Nenonen and C. Laird: Acta Metall. 33 (1985), 12, 2129.

5) K. Kimura, K. Fujiyama, T. Inukai, I. Murakami and N. Okabe: Microstructure and Mechanical Properties of Aging Materials, ed. by P. K. Liaw et al., TMS, Warrendale, PA, (1993), 49.

6) Z. Qu and K. H. Kuo: Metall. Trans. A, 12A (1981), 1333.

7) N. S. Cheruvu and B. B. Seth: Metall. Trans. A, 20A (1989), 2345.

8) T. Wada and V. A. Biss: Metall. Trans. A, 14A (1983), 845.

9) C. D. Buscemi, B. L. Jack, J. W. Skogsberg and W. E. Erwin: J. Mater. Sci., 113 (199I), 329.

10) A. Joarder, D. S. Sarma and N. S. Cheruvu: Metall. Trans. A, 22A (1991), 1811 .

11) J. H. Bulloch and J. J. Hickey: Microstructure and Mechanical Properties of Aging Materials, ed. by P. K. Liaw et al., TMS Warrendale, PA, (1993), 41.

12) T. Ogura, A. Makino and T. Matsumoto: Metall. Trans. A, 15A (1984), I563.

13) ASTM Book of Standards, ASTM Standard E-23, American Society for Testing and Materials, Philadelphia, PA, 03.01 (1987).

14) R. M. Goldhoff and H. J. Beattie, Jr.: Trans. Metall. Soc. AIME, 223 (1965), 1743

15) M. C. Murphy and G. D. Branch: J. Iron Steel Inst., 207 (1969), 1347.

16) K. R. Williams and B. Wilshire: Mater. Sci. Eng., 47 (1981), 151.

17) P. K. Liaw, M. G. Burke, A. Saxena and J. D. Landes: Metall. Trans, $A, 22 \mathrm{~A}$ (1991), 455

18) G. E. Dieter: Mechanical Metallurgy, 2nd Ed., McGraw-Hill, New York, (1976), 498. 